\title{
Functional Properties and Microstructure Development of Micro-Nano Fe/MgO Composite
}

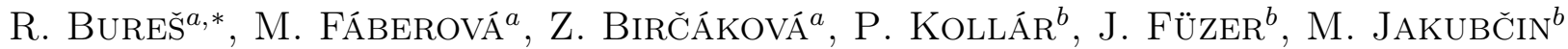 \\ AND P. SLOVENSKÝ ${ }^{b}$ \\ ${ }^{a}$ Institute of Materials Research, Slovak Academy of Sciences, Watsonova 47, 04001 Košice, Slovak Republic \\ ${ }^{b}$ Institute of Physics, Faculty of Science, Pavol Jozef Šafárik University in Košice, \\ Park Angelinum 9, 04154 Košice, Slovak Republic
}

(Received January 23, 2019; revised version January 13, 2020; in final form January 23, 2020)

\begin{abstract}
Micro-nano soft magnetic composite $\mathrm{Fe} / x \mathrm{MgO}$ was prepared by press and sinter method. The microstructure and functional properties were investigated in dependence on particle size of $\mathrm{MgO}$, as well as on $\mathrm{MgO}$ content ratio. Changes of electrical and magnetic properties were clarified on the background of the microstructure development. Particle size of the dielectric $\mathrm{MgO}$ phase significantly influenced the densification process, as well as the quality of insulation of each Fe particle from the others, hence the magnetic properties of composite. Significant influence of $\mathrm{MgO}$ particle size was observed at frequency of $1 \mathrm{MHz}$. Value of real part of complex permeability increased with increasing $\mathrm{MgO}$ particle size in this order: $10 \mathrm{~nm}, 1000 \mathrm{~nm}$ and the highest value was achieved in $\mathrm{Fe} / 3 \mathrm{MgO}$ with $30 \mathrm{~nm} \mathrm{MgO}$ particles.
\end{abstract}

DOI: 10.12693/APhysPolA.137.283

PACS/topics: 81.05.--t, 75.50.--y, 62.20.--x

\section{Introduction}

Relatively new and remarkable kind of soft magnetic materials named soft magnetic composites (SMCs) consists of small ferromagnetic particles electrically insulated from each other. They provide some advantages in comparison with traditional materials (electrical steels or soft magnetic ferrites), as the three-dimensional isotropic physical properties, lower total energy losses at medium to higher frequencies due to lower classical eddy current losses, relatively high saturation induction and the near net shape powder metallurgy fabrication process beneficial from the economical, as well as ecological view [1-4]. SMCs find increasing application potential as cores for transformers, electromotors, generators, electromagnetic circuits, sensors, actuation devices, or induction coils. Each application often requires specific material properties, which can be tuned in wide ranges by the composition of SMC and technological process parameters [1-4].

The most used ferromagnetic component for SMC is the iron powder mainly because of the low cost and high saturation induction. As insulators the inorganic (phosphates, oxides) or the organic (thermoplastics, thermosets) materials are used. Parameters of the heat treatment, relieving internal stresses induced during the compaction of insulated ferromagnetic powder particles, depend on the chosen materials [2,3].

The quality of insulation of ferromagnetic particles is essential, because of its significant influence on the resulting properties of composite, namely the better

*corresponding author; e-mail: rbures@saske.sk the insulation, the lower the classical eddy current losses as these currents are closed within the particles $[3,4]$. On the other hand, the negative effect of the SMC structure is the formation of inner demagnetizing fields coming from the surface magnetic poles on insulated ferromagnetic particles [4-6], lowering the magnetic permeability of SMC.

SMC structure observed at the cross-section is based on ferromagnetic micro-islands surrounded by dielectric network. From the viewpoint of the permeability it is desired to achieve thickness of the network as thin as possible. In case of resistivity, the network thickness is limited by effectiveness of the electric insulation. Composites with specific 3D inhomogeneous microstructure based on hierarchic micro-nano structural constituents can be exploited to improve mechanical properties. SMC can be defined as 3D continuous dielectric reinforcementrich phase with isolated ferromagnetic phase, only the reinforcement-rich phase is continuous to form a grain boundary-like network [7].

The aim of this work was to investigate the powder hierarchic micro-nano composite based on ferromagnetic micro-particles and dielectric nanoparticles, focusing on clarification of the evolution of microstructure and functional properties of pressed and sintered powder composite.

\section{Experimental materials and methods}

Pure iron powder ASC100.29 (median particle size of $100 \mu \mathrm{m})$ supplied by Höganäs AB Sweden was used as primary ferromagnetic component of the composite. Secondary component was magnesium oxide powder. $\mathrm{MgO}$ particle size was 10, 30, and $1000 \mathrm{~nm}$ with narrow particle size distribution. $\mathrm{Fe}$ and $\mathrm{MgO}$ powders were dry 
mixed using Resonant acoustic mixer LabRAM. Fe microparticles were covered by smaller $\mathrm{MgO}$ nanoparticles, $\mathrm{Fe} / \mathrm{MgO}$ mixture was shaped by uniaxial die, pressing to the shape of cylinder with diameter of $10 \mathrm{~mm}$ and height of $3 \mathrm{~mm}$, prism of size $4 \times 5 \times 20 \mathrm{~mm}^{3}$ and ring sample with outer diameter of $24 \mathrm{~mm}$, inner diameter of $18 \mathrm{~mm}$ and height of $3 \mathrm{~mm}$. Green compact pressed at pressure of $600 \mathrm{MPa}$ was sintered at $600^{\circ} \mathrm{C}$ in dry air atmosphere for $60 \mathrm{~min}$ in chamber muffle furnace.

The $\mathrm{Fe} / \mathrm{MgO}$ composites were prepared with content of $1,2,3,5,7$, and $10 \mathrm{wt} \% \mathrm{MgO}$. Microstructure was investigated by light and electron microscopy using LM Nikon LVDia and SEM Jeol JSM 7000F. Resistivity was measured using 4 point probe method by Mitsubishi Loresta AX. Coercive force meter LINKJOIN ATS-320 was used for the measurement of the coercive field of composites at $30 \mathrm{kA} / \mathrm{m}$ in an open magnetic circuit. Real part of complex permeability was measured at the frequencies $1 \mathrm{kHz}$ and $1 \mathrm{MHz}$ by impedance spectroscopy using an impedance analyzer HP 4194A with the contact electrodes in two-terminal connection configuration.

\section{Results and discussion}

\subsection{Density}

Relative density of the prepared composites depends on $\mathrm{MgO}$ particle size as it is documented in Fig. 1. Small addition of $\mathrm{MgO}$ up to $2 \mathrm{wt} \%$ slightly increases relative density of green compacts. Higher content of $\mathrm{MgO}$ above $5 \mathrm{wt} \%$ decreases green density. $10 \mathrm{~nm} \mathrm{MgO}$ nanoparticles influence the relative density significantly less than $\mathrm{MgO}$ particles size of $30 \mathrm{~nm} .1000 \mathrm{~nm} \mathrm{MgO}$ particles have the most negative influence on relative green density of the composite. Sintering does not lead to significant increase of relative density of the composite, because creation of $\mathrm{Fe}-\mathrm{Fe}$ sintering necks is suppressed. Sintered density of the composite based on $1000 \mathrm{~nm} \mathrm{MgO}$ particles is slightly higher in comparison to composite based on $30 \mathrm{~nm}$ particles. The highest is the sintered density of the composite based on $10 \mathrm{~nm} \mathrm{MgO}$ particles. This fact indicates partial formation of $\mathrm{Fe}-\mathrm{Fe}$ interparticle connections during sintering of $\mathrm{Fe} / x \mathrm{MgO}$ based on $\mathrm{MgO}$ particles size of $10 \mathrm{~nm}$.

\subsection{Resistivity}

Results of the specific resistivity measurement confirm different effectiveness of $\mathrm{MgO}$ nanoparticles to create continuous dielectric coating on Fe microparticles in dependence on $\mathrm{MgO}$ particle size. In Fig. 2a it is shown that the most effective is $\mathrm{MgO}$ size of $30 \mathrm{~nm}$. Specific resistivity of green compact rapidly increase with increasing content of $\mathrm{MgO} 30 \mathrm{~nm}$ particles in cold pressed composite. The smallest $\mathrm{MgO} 10 \mathrm{~nm}$ particles form significantly less effective dielectric network in comparison to green compact based on $\mathrm{MgO} 30 \mathrm{~nm}$, because the formation of $\mathrm{Fe}-\mathrm{Fe}$ interparticle connections is significant. Tendency curve of the resistivity of $\mathrm{MgO} 1000 \mathrm{~nm}$ particles based
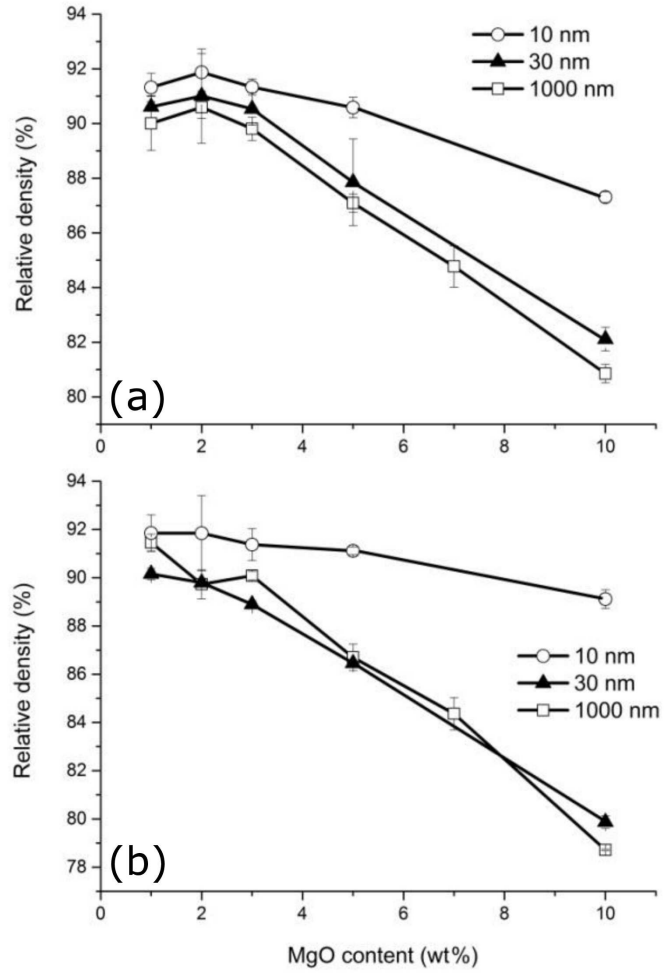

Fig. 1. Relative density of $\mathrm{Fe} / \mathrm{MgO}$ : (a) green compacts, (b) sintered composites.
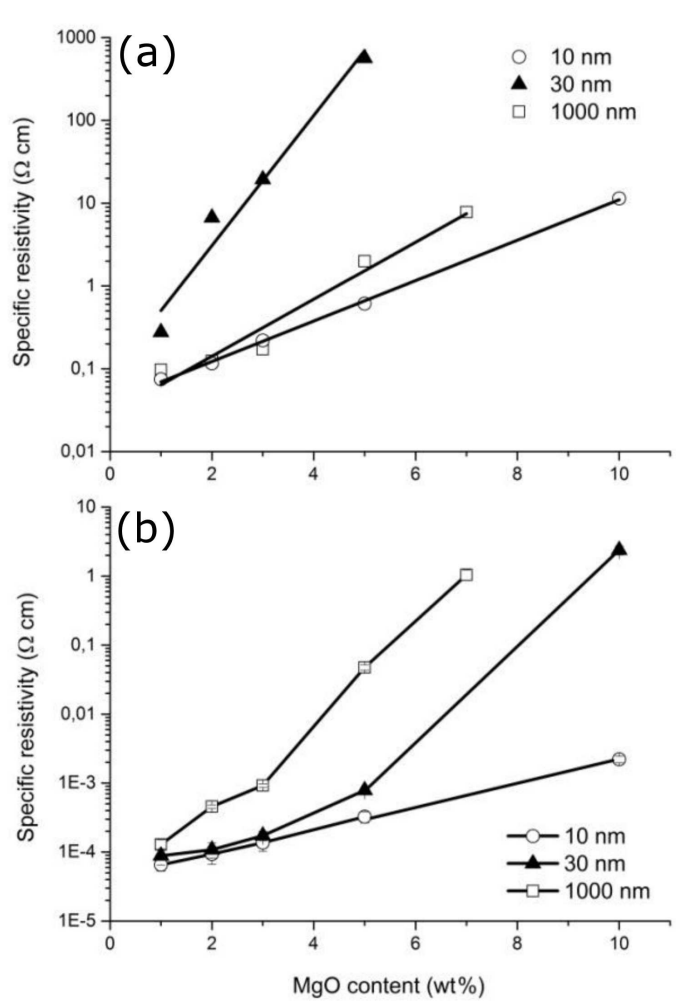

Fig. 2. Specific resistivity of Fe/MgO: (a) green compacts, (b) sintered composites. 
composite is close to the curve of $\mathrm{MgO} 10 \mathrm{~nm}$. Sintering process leads to decrease of the resistivity values of all experimental composites as it is shown in Fig. 2b. Good level of resistivity values are preserved in $\mathrm{MgO} 30 \mathrm{~nm}$ based composites, but resistivity of $\mathrm{MgO} 1000 \mathrm{~nm}$ composites are significantly higher after sintering. It is assumed to be caused by higher porosity probably arising among $1000 \mathrm{~nm} \mathrm{MgO}$ particles. Analysis of the green and sintered resistivity of experimental composites confirms changes in densification processes. Evaluation based on density and specific resistivity could lead to preliminary result that the most suitable size of $\mathrm{MgO}$ particles is nearly size of $1 \mu \mathrm{m}$.

\subsection{Magnetic properties}

Analyses of the magnetic properties change show on functional properties of prepared $\mathrm{Fe} / x \mathrm{MgO}$ composites. In Fig. 3 the coercive field in dependence on $\mathrm{MgO}$ content for different $\mathrm{MgO}$ particle size is shown. Composite based on $\mathrm{MgO} 30 \mathrm{~nm}$ particles provides the lowest coercive field values of green and sintered composite. In green compact, coercive field value reflects a level of residual stresses after cold pressing. Residual stresses could be relieved in sintering process above relaxation temperature. Sintering temperature $600{ }^{\circ} \mathrm{C}$ is enough to relieve residual stresses in iron. Coercive field decreased after sintering as it is shown in Fig. 3b. Increased coercive field values at higher content of $\mathrm{MgO}$ were observed. This phenomenon is dependent on the size of $\mathrm{MgO}$ particles. $\mathrm{MgO} 1000 \mathrm{~nm}$ particles in the composite leads to more rapid increasing of coercive field in comparison to smaller $\mathrm{MgO} 30 \mathrm{~nm}$ particles. Increasing coercive field is probably caused by thermal stresses due to different thermal expansion coefficient of $\mathrm{MgO}$ and Fe. Different $\mathrm{MgO}$ particle size creates different $\mathrm{MgO}$ phase distribution in the composite. It can be expected that thermal stresses are more significant in case of irregular distribution of $\mathrm{MgO}$ in the composite. Coercive field can be considered as an indicator of $\mathrm{MgO}$ agglomeration in the composite.

In Fig. 4 the real part of complex permeability at frequency $1 \mathrm{kHz}$ (Fig. 4a) and $1 \mathrm{MHz}$ (Fig. 4b) is plotted as a function of $\mathrm{MgO}$ insulation content in sintered composite material, for three particle sizes of $\mathrm{MgO}$ nanopowder.

In case of SMCs the real part of complex permeability at frequency $1 \mathrm{kHz}$ is equal to the static initial permeability [4] and was found to be decreasing with the increase of $\mathrm{MgO}$ content for all $\mathrm{MgO}$ particle sizes, as expected. It is mainly due to the increasing inner demagnetizing fields arising from the surface magnetic poles on the iron particles insulated from each other [4-6], as the used ferromagnetic material and preparation process was the same and samples differed mainly in the insulation part (the content and particle size of $\mathrm{MgO}$, as well as $\mathrm{MgO}$ distribution and porosity within composite). The higher the non-ferromagnetic content in SMC (insulation and pores), the larger the spaces between ferromagnetic particles causing the cut-off of the magnetic flux through
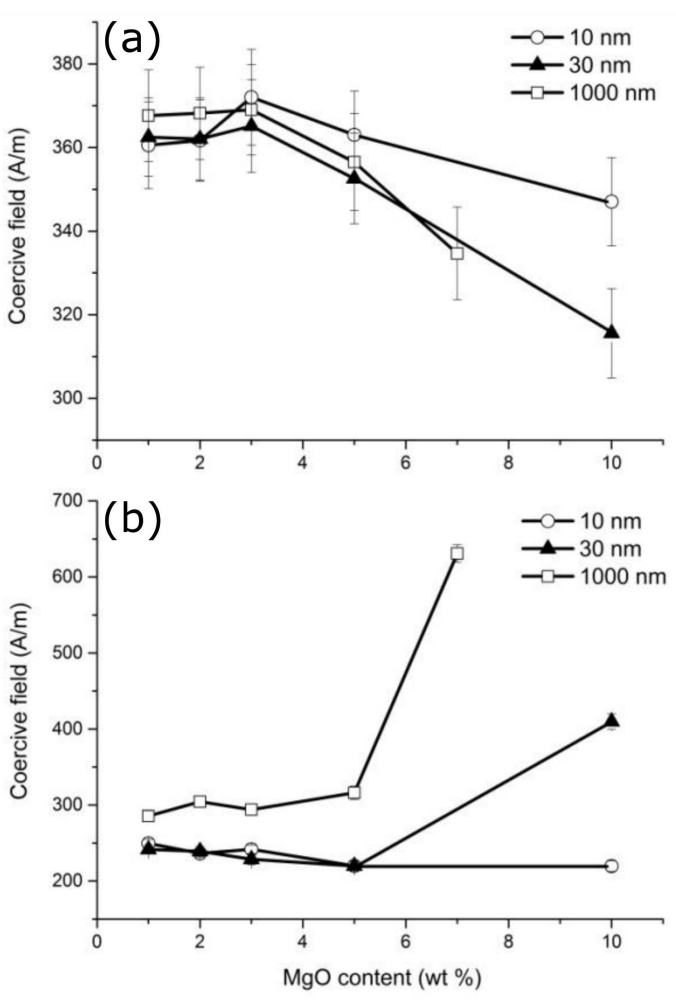

Fig. 3. Coercive field of $\mathrm{Fe} / \mathrm{MgO}$ : (a) green compacts, (b) sintered composites.
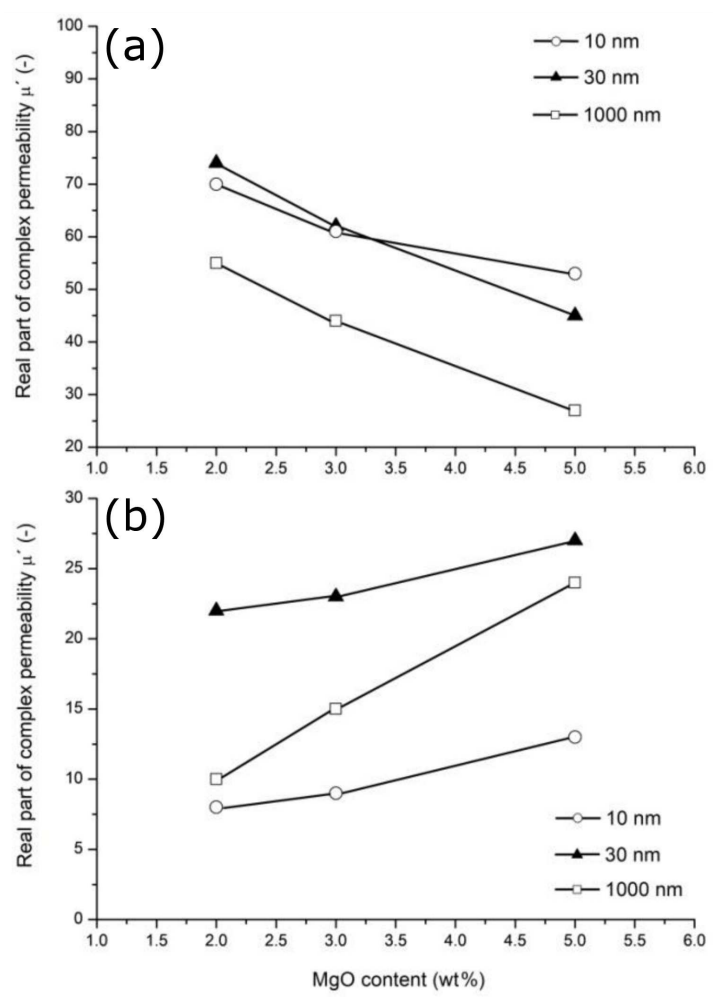

Fig. 4. Real part of complex permeability of sintered $\mathrm{Fe} / \mathrm{MgO}$ composites at frequency (a) $1 \mathrm{kHz}$, (b) $1 \mathrm{MHz}$, for 10,30 , and $1000 \mathrm{~nm} \mathrm{MgO}$ particle size. 
SMC and lowering the magnetic interaction between iron particles. Finally it reflects in lower number of movable domain walls in material and hence lower value of permeability $[4,5]$.

Magnetic permeability is in general negatively influenced also by various defects in ferromagnetic material as dislocations, inclusions or voids, grain boundaries and internal stresses, all hindering the domain wall motion $[5,8]$.

On the other hand, the tendency of the real part of complex permeability at frequency $1 \mathrm{MHz}$ is opposite, it is increasing with the increase of insulation content for all $\mathrm{MgO}$ particle sizes. The higher is the insulation content in SMC, the higher is the stability of the real part permeability to higher frequencies, due to the higher specific electrical resistivity of such SMC (the resonant frequency at which the real part permeability drops to its half value is proportional to the specific resistivity of material [9]). The specific resistivity of sintered samples is in Fig. $2 \mathrm{~b}$ - it is increasing with the increase of $\mathrm{MgO}$ content as expected, but furthermore we can observe the higher resistivities for $30 \mathrm{~nm}$ and $1000 \mathrm{~nm} \mathrm{MgO}$ particle sizes compared to the $10 \mathrm{~nm} \mathrm{MgO}$. The electrical resistivity of SMC depends on the quality of insulation of every ferromagnetic particle from each other, hence we can conclude the insulation of $10 \mathrm{~nm} \mathrm{MgO}$ powder is the least effective one compared to $30 \mathrm{~nm}$ and $1000 \mathrm{~nm}$, as $10 \mathrm{~nm} \mathrm{MgO}$ particles are probably too small to create a layer completely covering iron particles and preventing electrical contacts between them. That is why in Fig. $4 \mathrm{~b}$ the permeability dependence for $10 \mathrm{~nm} \mathrm{MgO}$ is of the lowest values. The $1000 \mathrm{~nm} \mathrm{MgO}$ powder particles conversely seem to be too large, causing the increase of porosity within SMC (reflected by the drop in real part permeability, Fig. 4a).

The most stable material for higher frequencies was found to be the SMC with $30 \mathrm{~nm} \mathrm{MgO}$ insulation (the highest permeability at $1 \mathrm{MHz}$, Fig. 4b), with concurrently the highest static permeability (Fig. 4a), concluding that the $30 \mathrm{~nm} \mathrm{MgO}$ particle sizes create the most effective insulation for iron-based composites.

\subsection{Microstructure}

Microstructure of the sintered $\mathrm{Fe} / \mathrm{MgO}$ composites consists from origin iron particles divided by more or less continuous $\mathrm{MgO}$ network. Secondary phase of the composite is based on sintered $\mathrm{MgO}$ as it is shown in Fig. 5 (EDS line analysis). After sintering in air atmosphere, interphase $\mathrm{Fe}-\mathrm{MgO}$ can contain $\mathrm{Fe}_{3} \mathrm{O}_{4}$ or non-stoichiometric $\mathrm{MgFe}_{2} \mathrm{O}_{4}$ - Table I (EDS point analysis) $[10,11]$. Distribution of the dielectric secondary phase has crucial influence on functional properties of the soft magnetic composite. SEM backscatter electrons (BSE) technique was used to obtain contrast between heavy $\mathrm{Fe}$ (light in BSE image) and light $\mathrm{Mg}$ and $\mathrm{O}$ elements (dark regions in BSE).

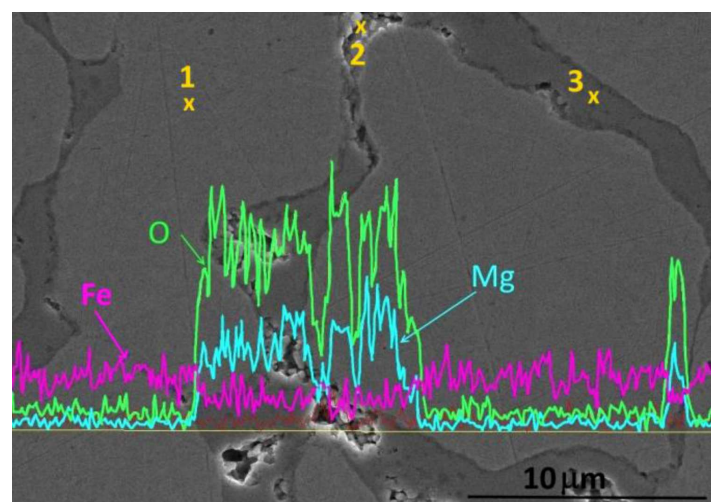

Fig. 5. Sintered $\mathrm{Fe} / 2 \mathrm{MgO}$ composite, SEM EDS line analysis of $\mathrm{Fe} / \mathrm{MgO} 30 \mathrm{~nm}$ interface.

TABLE I

EDS point analysis of $\mathrm{Fe} / \mathrm{MgO} 30 \mathrm{~nm}$ interface

\begin{tabular}{c|c|c|c}
\hline \hline $\begin{array}{c}\text { EDX analysis } \\
\text { [wt\%] }\end{array}$ & $\mathrm{Fe}$ & $\mathrm{Mg}$ & $\mathrm{O}$ \\
\hline 1 & 100 & - & - \\
2 & 60.48 & 14.36 & 25.16 \\
3 & 66.05 & 10.27 & 23.67
\end{tabular}

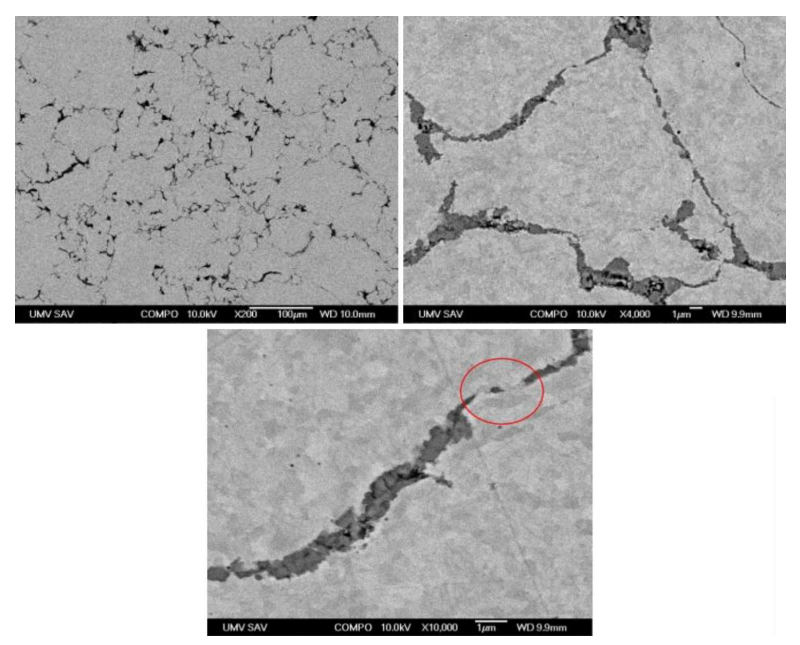

Fig. 6. Microstructure of $\mathrm{Fe} / 2 \mathrm{MgO} 10 \mathrm{~nm}$ composite, SEM backscattering.

In Fig. 6 the microstructure of $\mathrm{Fe} / 2 \mathrm{MgO}(10 \mathrm{~nm})$ composite is shown. Minimal thickness of the dielectric layer is limited by $\mathrm{MgO}$ particle size. Small $\mathrm{MgO} 10 \mathrm{~nm}$ particles cover the iron microparticle by very thin layer, which follow all surface features of origin iron particles. Surface roughness of the iron microparticles and small $\mathrm{MgO}$ $10 \mathrm{~nm}$ particles lead to breaking of $\mathrm{MgO}$ layer. Iron-iron short bridges are created in the sintering process as it is documented in Fig. 6 - red marked detail. This Fe-Fe connections decrease the resistivity, but density of the composite is increased by sintering process. 




Fig. 7. Microstructure of $\mathrm{Fe} / 2 \mathrm{MgO} 30 \mathrm{~nm}$ composite, SEM backscattering.



Fig. 8. Microstructure of $\mathrm{Fe} / 2 \mathrm{MgO}(1000 \mathrm{~nm})$ composite, SEM backscattering.

In case of $\mathrm{Fe} / \mathrm{MgO} 30 \mathrm{~nm}$ composite in Fig. 7 it is possible to observe continuous $\mathrm{MgO}$ network. $\mathrm{MgO}$ nanoparticles of size $10 \mathrm{~nm}$ create effective barrier to creation of Fe-Fe bridges during the sintering, while thickness of the $\mathrm{MgO}$ layer is from 1 to $2 \mu \mathrm{m}$ at content of $2 \mathrm{wt} \% \mathrm{MgO}$. Porosity is located to small pores in the interfaces of the composite.

Relatively regular distribution of the $\mathrm{MgO}$ in the composite is damaged if large $\mathrm{MgO} 1000 \mathrm{~nm}$ particles are applied in the composite as it is shown in Fig. 8. Large cubic $\mathrm{MgO}$ particles are pin up on the surface of iron particles in mixing process. Cold pressing imprint rigid $\mathrm{MgO}$ $1000 \mathrm{~nm}$ particles to iron particles, while Fe particle is deformed. Microstructure of the composite is recovered, residual stresses are relieved in sintering process. Large $\mathrm{MgO} 1000 \mathrm{~nm}$ particles avoid to create $\mathrm{Fe}-\mathrm{Fe}$ connections, causing decreased density of the composite.

Identified densification mechanism of the $\mathrm{Fe} / \mathrm{MgO}$ composite for different size of $\mathrm{MgO}$ particles is schematically depicted in Fig. 9. Application of these densification mechanism and microstructure development can be expected in case of the micro-nano powder systems based on microparticles with ability to plastic deformation and rigid nanoparticles. Specific densification mechanism together with secondary phase content ratio are the driving

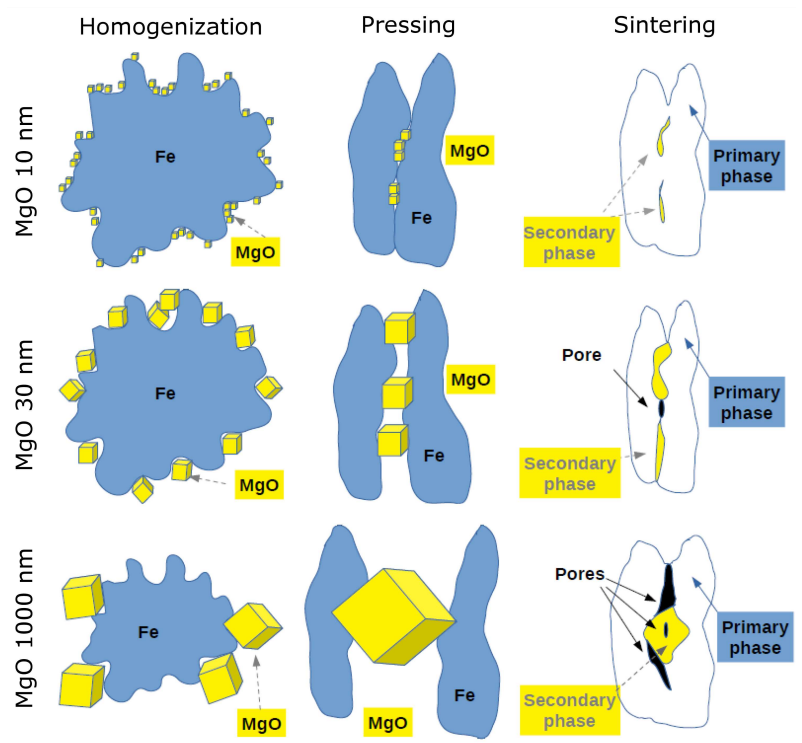

Fig. 9. Microstructure evolution mechanism of micronano powder composite based on different particle size of secondary constituent.

force for significant modification of the functional properties, as well as the mechanical properties of soft magnetic composite, as it is discussed in other work [11, 12].

\section{Conclusions}

Hierarchic micro-nano composite $\mathrm{Fe} / x \mathrm{MgO}$ (where $x$ is $1,2,3,5,7$, and $10 \mathrm{wt} \%$ ) was prepared by press and sinter method. Particle size of the secondary dielectric $\mathrm{MgO}$ nanophase significantly influences the densification process as well as the quality of insulation of each Fe microparticle from the others, hence the final properties of composite. Densification process of $\mathrm{Fe}-\mathrm{MgO}$ powder mixture is well supported by $10 \mathrm{~nm} \mathrm{MgO}$ particles. Specific resistivity increases with increasing $\mathrm{MgO}$ particle size, but distribution of the dielectric phase as well as size and shape distribution of the pores are different. Continuous $\mathrm{MgO}$ network creates effective barrier to creation of iron-iron bridges during the sintering in case of $\mathrm{Fe} / \mathrm{MgO}$ composite based on $30 \mathrm{~nm} \mathrm{MgO}$ particles. $\mathrm{Fe} / 3 \mathrm{MgO} 30 \mathrm{~nm}$ composite was found to be the material with suitable distribution of $\mathrm{MgO}$ to create iron based soft magnetic composite stable for higher frequencies, supported by the magnetic properties analyses - the coercive field and the real part of complex permeability.

\section{Acknowledgments}

This work was supported by the Slovak Research and Development Agency under Grant APVV 0115-15 and the Scientific Grant Agency of the Ministry of Education, Science, Research and Sports and Slovak Academy of Sciences under Grant VEGA 2/0108/18. 


\section{References}

[1] K.H.J. Buschow, Concise Encyclopedia of Magnetic and Superconducting Materials, Elsevier, Oxford 2005, eBook.

[2] K.J. Sunday, M.L. Taheri, Metal Powder Rep. 72, 425 (2017).

[3] B. Ślusarek, B. Jankowski, K. Sokalski, J. Szczygłowski, J. Alloys Comp. 581, 699 (2013).

[4] E.A. Périgo, B. Weidenfeller, P. Kollár, J. Füzer, Appl. Phys. Rev. 5, 031301 (2018).

[5] E. Kneller, Ferromagnetismus, Springer, Berlin 1962.

[6] J.-L. Mattei, M. Le Floc'h, J. Magn. Magn. Mater. 257, 335 (2003).
[7] L.J. Huang, L. Geng, H-X. Peng, Prog. Mater. Sci. 71, 93 (2015).

[8] S. Chikazumi, Physics of Ferromagnetism, 2nd ed., Oxford University Press, New York 1999, eBook.

[9] F. Mazaleyrat, L.K. Varga, J. Magn. Magn. Mater. 215-216, 253 (2000).

[10] N.M. Deraz, O.H. Abd-Elkader, Int. J. Electrochem. Sci. 8, 8632 (2013).

[11] R. Bureš, M. Fáberová, P. Kollár, J. Füzer, S. Dobák, F. Onderko, P. Kurek, Acta Phys. Pol. A 131, 780 (2017).

[12] R. Bureš, M. Fáberová, P. Kurek, Powder Metall. Progr. 18, 103 (2018). 